\title{
Smokeless Tobacco and Oral Cancer in South Asia: A Systematic Review with Meta-Analysis
}

\author{
Zohaib Khan, ${ }^{1,2}$ Justus Tönnies, ${ }^{1}$ and Steffen Müller ${ }^{1}$ \\ ${ }^{1}$ Leibniz Institute for Prevention Research and Epidemiology-BIPS, Achterstraße 30, 28359 Bremen, Germany \\ ${ }^{2}$ Khyber Medical University, Peshawar 25000, Pakistan
}

Correspondence should be addressed to Zohaib Khan; khan@bips.uni-bremen.de

Received 7 February 2014; Revised 7 May 2014; Accepted 8 June 2014; Published 6 July 2014

Academic Editor: Lance A. Liotta

Copyright (C) 2014 Zohaib Khan et al. This is an open access article distributed under the Creative Commons Attribution License, which permits unrestricted use, distribution, and reproduction in any medium, provided the original work is properly cited.

\begin{abstract}
Introduction. Smokeless tobacco is considered one of the major risk factors for oral cancer. It is estimated that over $90 \%$ of the global smokeless tobacco use burden is in South Asia. This paper aims to systematically review publications reporting epidemiological observational studies published in South Asia from 1984 till 2013. Methods. An electronic search in "Medline" and "ISI Web of Knowledge" yielded 734 publications out of which 21 were included in this review. All publications were assessed for quality using a standard quality assessment tool. Effect estimates (odds ratios (OR)) were abstracted or calculated from the given data. A random effects meta-analysis was performed to assess the risk of oral cancer with the use of different forms of smokeless tobacco. Results and Conclusion. The pooled OR for chewing tobacco and risk of oral cancer was 4.7 [3.1-7.1] and for paan with tobacco and risk of oral cancer was 7.1 [4.5-11.1]. The findings of this study suggest a strong causal link between oral cancer and various forms of smokeless tobacco. Public health policies in affected countries should consider SLT specific cessation programs in addition to campaigns and activities incorporated into smoking cessation programs.
\end{abstract}

\section{Introduction}

Oral cancer is one of the most common noncommunicable diseases worldwide with an estimated increase of 275,000 new cases each year [1]. Oral cancer is the term used for cancers that form in tissues of the oral cavity (the mouth) or the oropharynx (the part of the throat at the back of the mouth) [2]. These along with other head and neck cancers are the sixth most prevalent type of cancer in the world $[3,4]$ and one of the leading causes of death in developing countries [5]. The countries of South Asian region including India, Pakistan, Afghanistan, Bangladesh, Sri Lanka, Bhutan, Nepal, Iran, and Maldives [6] are particularly affected, with oral cancer ranking either first or second with regard to different types of cancer prevalence in these countries [7].

The reasons for the high prevalence of head and neck cancers in South Asia have been investigated to some extent but, as is the case with most developing countries, a lack of research infrastructure has put constraints on studying the epidemiology of these conditions in the context of
South Asia [8]. One of the major risk factors associated with the high prevalence of head and neck cancer and oral potentially malignant diseases (OPMD) in this region is smokeless tobacco (SLT) [9]. It is estimated that over $90 \%$ of the global smokeless tobacco use burden is in South East Asia [10]; around 100 million people use smokeless tobacco in India and Pakistan alone [11]. SLT is used in many forms varying from chewing tobacco not mixed with any other ingredient to a mixture of tobacco with other ingredients such as in betel quid, areca nut with tobacco, Naswar, paan-masala with tobacco, Gutkha, Khaini, and Mishri $[12,13]$. Smokeless tobacco contains around 28 known carcinogens. These include the nonvolatile alkaloid-derived tobacco-specific $\mathrm{N}$-nitrosamine and $\mathrm{N}$-nitrosamino acids as the major group while volatile tobacco-specific nitrosamines, volatile aldehydes, and some poly nuclear agents have also been shown to be present in smokeless tobacco [14].

With such a high prevalence of both SLT use and oral cancer in the South Asian region, it is of utmost importance that epidemiological research is carried out to carefully 
assess their detailed relationship. Two published reviews coauthored by IARC researchers have focused on overall associations found in studies worldwide [15, 16]. Several overviews originating from South Asia have been published on oral cancer and smokeless tobacco $[15,17-26]$ but to date no systematic review of the published literature on association of oral cancer with different forms of smokeless tobacco focusing specifically on South Asia has been conducted. This paper aims to address the issue by systematically reviewing publications reporting epidemiological observational studies carried out/published in the South Asian region during the last 30 years, that is, published after 1984 on the use of all forms of SLT and its relationship with oral cancer.

\section{Methods}

2.1. Search Strategy. An electronic search was carried out in "Medline" and "ISI Web of Knowledge" in August 2013. Various combinations of the terms "oral premalignant disease," "oral precancer," "leukoplakia," "erythroplakia," "submucous fibrosis," "lichen planus," "oral cancer," "oral carcinoma," "mouth neoplasm," "head and neck cancer," "squamous cell carcinoma of the oral cavity," "carcinoma lip," "carcinoma tongue," "oral neoplasms," and "head and neck neoplasms"; "smokeless tobacco," "Naswar," "paan," "snuff," "oral snuff," "chewing tobacco," "betel quid," "areca nut," and "Gutkha"; "Pakistan," "India," "Bangladesh," "Iran," "Sri Lanka," "Afghanistan," "Bhutan," "Nepal," "Maldives" were used. The terms for different OPMDs were included in the search process as sometimes these conditions are studied together with oral cancer. No filters were used during the electronic searches.

2.2. Publication Selection. The following selection criteria were applied to all the publications returned by the electronic searches to be included in the review.

\subsubsection{Inclusion Criteria. Inclusion criteria are as follows:}

(i) papers published after 1984,

(ii) epidemiological observational study in humans of cohort or case-control design,

(iii) studies carried out in "South Asia" according to the United Nations geographical region classification (including the following countries: India, Pakistan, Afghanistan, Bangladesh, Sri Lanka, Bhutan, Nepal, Iran, and Maldives),

(iv) reported outcome or one of the reported outcomes is oral cancer or head and neck cancer, and

(v) exposure to paan, Gutkha, betel nut, areca nut, or any other type of smokeless tobacco.

\subsubsection{Exclusion Criteria. Exclusion criteria are as follows.}

(i) Studies reporting oesophageal, base of the tongue, and salivary glands cancers were excluded.

(ii) Studies involving laboratory research and molecular/genetic epidemiology were excluded.
The selection process was done in three steps: first, the titles of all publications were scanned and relevant publications selected. The next step involved reading the abstracts of the publications selected in the first step. Full text of the publications identified during step two were then obtained. The selected publications were then divided into three groups according to their reported outcomes: (1) OPMD as an outcome, (2) oral cancer as an outcome, and (3) OPMD and oral cancer as an outcome; publications reporting only OPMDs as an outcome were excluded at this stage. Reference lists of the selected publications were scanned to identify any additionally relevant publications.

2.3. Quality Assessment. All selected publications were assessed for their quality on the basis of the "Effective Public Health Practice Project Quality Assessment Tool for Quantitative Studies" [27]. Studies were ranked as "strong," "moderate," and "weak" after being assessed on six parameters, that is, selection bias, study design, confounding, blinding, data collection methods, and withdrawals and dropouts. Quality assessment was carried out by two authors independently and the results were later compared. Any differences were discussed in the presence of all three authors and a final decision was reached by mutual consensus.

2.4. Data Extraction. Data extraction was carried out between October and December 2013. First, data regarding the study type, location of the conducted study, sample size, year of publication, exposure, outcome, and the effect size were tabulated separately by two authors and later compared in the presence of all three authors. The data were then divided into two broad groups according to the difference in the type of SLT exposure, that is, "paan or betel quid with tobacco" and "chewable tobacco which included all types of smokeless tobacco other than paan." Adjusted odds ratios (OR) along with their 95\% confidence intervals (95\% $\mathrm{CI}$ ), if reported, were recorded. In studies, where OR were not reported but the data required to calculate them were available, OR were calculated using a Mantel-Haenszel ( $\mathrm{MH})$ approach, thus providing us with weighted OR across the different strata reported. However, if the paper did not report an adjusted $\mathrm{OR}$ and the data given were too scarce to calculate $\mathrm{MH}-\mathrm{OR}$, then the crude OR as reported in the paper or calculated from the given data was recorded. OR were also recorded or calculated for male and females separately, total duration of the habit in years, and frequency of daily use. Again efforts were made to record the most adjusted measure, whenever permissible. Standard errors of the natural logs of the OR were calculated either from the $95 \% \mathrm{CI}$ of the respective $\log \mathrm{OR}$ or by using the formula $\mathrm{SE}\left(\ln \mathrm{OR}_{\mathrm{MH}}\right)=$ $\sqrt{\sum\left(b_{i} c_{i} / N_{i}\right)^{2} v_{i} /\left(\sum b_{i} c_{i} / N_{i}\right)^{2}}$ when a MH-OR was calculated.

2.5. Meta- and Heterogeneity Analysis. During the data extraction stage it had become obvious that there was major heterogeneity regarding methodological and other parameters among the selected publications. Nevertheless all data were entered into Rev Man 5.2 [28] and meta-analyses 
performed across all exposure categories, and their effect on oral cancer separately and combined was recorded. This was done with the inverse variance method using both fixed and random effects. This also provided the $I^{2}$ estimates of statistical heterogeneity. The $I^{2}$ estimate was used to assess heterogeneity as it provides a better estimate for quantifying heterogeneity. Heterogeneity was considered low if the $I^{2}$ estimate was below $25 \%$, moderate if it was between 25 and $50 \%$, high if it was between 50 and $75 \%$, and very high above the value of $75 \%$. Due to a very high level of heterogeneity, random effect meta-analysis has been used for this review. Sensitivity and influence analysis were done by excluding one study at a time and checking its effect on the pooled estimate and the heterogeneity, but this had little effect on lowering the $I^{2}$ statistic.

Meta-analyses were performed for overall estimates, casecontrol studies, studies with hospital controls, cohort studies, studies from India only, studies from southern India only, studies for Maharashtra state, studies adjusting for smoking and/or alcohol, studies with moderate quality, and studies involving only men.

2.6. Narrative Synthesis. For the categories where the data was incomplete, unavailable, or calculated using different methods, for example, the exposure response categories, a narrative synthesis was done. The synthesis highlights the highest and lowest estimates in general, according to gender and for studies that had done adjustment for alcohol and/or smoking.

\section{Results}

A total of 734 publications were identified from both database searches (Medline, ISI Web of Knowledge) (Figure 1). One more paper was identified from a supplementary web search but it just reported the findings from one of the included studies and hence was excluded. After the first round of exclusion 137 publications remained; after reading the abstracts, 38 publications were selected and their full text versions obtained. 4 publications were excluded after examining the full paper. This left us with a total of 34 publications. 21 publications reported oral cancer as the outcome or one of the outcomes and 13 publications reported just OPMD as the outcome. The publications corresponding to OPMD were excluded at this stage.

The 21 publications [29-49] for oral cancer included in this review correspond to 19 different studies and three studies were of cohort design while the remaining were of case-control design (Table 1). Two studies were carried out in Pakistan and the rest in India. 13 publications were published in or after the year 2000 while the remaining publications were published before the year 2000, the oldest publication being from 1989.

11 of the selected publications reported or contained data on paan with tobacco (betel quid) as a risk factor whereas 14 publications reported or contained data on chewing tobacco other than paan or without specifying any particular type of

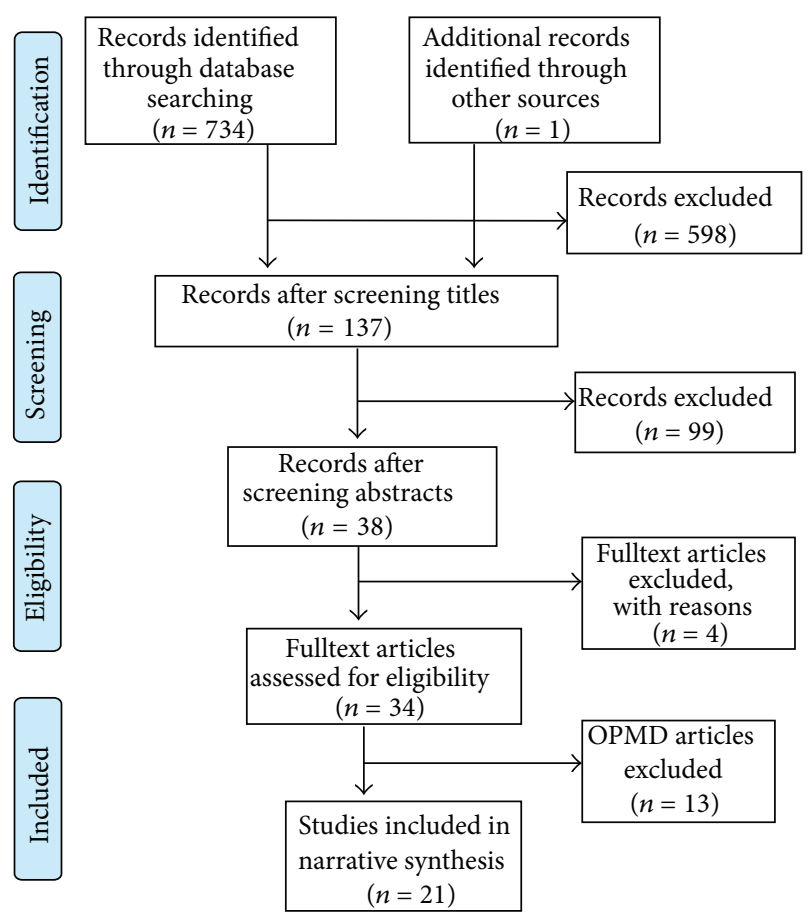

FIGURE 1: Flow chart of selection process of articles included in the review.

SLT. 11 publications reported or contained data stratified by sex.

Data regarding daily frequencies of smokeless tobacco use were reported in 14 publications, while data on the total duration of the habit was reported in 10 publications. Table 1 includes all selected studies for oral cancer and their features along with the quality assessment result for each study.

The values for $I^{2}$ statistic ranged from $77 \%$ to $96 \%$ when pooling studies across different strata. Core findings from the included publications are given in Table 1. Additional characteristics of the included studies are presented in the supplementary Table 1 available online at http://dx.doi.org/10.1155/2014/394696.

For the purpose of clarity and taking into consideration the considerable difference between the outcome estimates related with the use of betel quid and other forms of SLT, we reviewed the relationship of oral cancer with SLT in two groups: (1) chewing tobacco of all kinds excluding betel quid or paan with tobacco and (2) betel quid or paan with tobacco.

3.1. Chewing Tobacco and Oral Cancer. Overall 14 publications reported different forms of chewing tobacco, predominantly Gutkha and chewing tobacco leafs (Table 2). Five publications reported OR that had been adjusted for smoking among other confounders. The adjusted OR ranged from 3.6 [2.5-5.6] [34] to 8.3 [5.4-13] [48]. The OR ranged from 1.2 [1.0-1.4] [47] to 12.9 [7.5-22.3] [33] among the publications in which either crude odds ratios were mentioned or a $\mathrm{MH}$ OR was calculated from the given data. The pooled OR for chewing tobacco and risk of oral cancer was 4.7 [3.1-7.1] (Figure 2). The studies where adjustment for alcohol and/or 
TABLE 1: Characteristics of included studies on oral cancer.

\begin{tabular}{|c|c|c|c|c|c|c|c|}
\hline Authors & Year & Location & Study type & $\begin{array}{c}\text { Sample Size } \\
\text { (cases/controls) } \\
\text { (Cohort size/oral }^{\text {cancer cases) })^{* *}}\end{array}$ & $\begin{array}{c}\text { Quality } \\
\text { assessment* }\end{array}$ & $\begin{array}{l}\text { Mean age } \\
\text { of cases }\end{array}$ & $\begin{array}{c}\text { Adjustment for } \\
\text { smoking and alcohol }\end{array}$ \\
\hline $\begin{array}{l}\text { Sankaranarayanan et al. } \\
\text { [29] }\end{array}$ & 1989 & India & Case-control & $228 / 453$ & Moderate & $\mathrm{n} / \mathrm{a}$ & Smoking and alcohol \\
\hline $\begin{array}{l}\text { Sankaranarayanan et al. } \\
\text { [30] }\end{array}$ & 1989 & India & Case-control & $187 / 895$ & Moderate & $\mathrm{n} / \mathrm{a}$ & Smoking and alcohol \\
\hline Goud et al. [32] & 1990 & India & Case-control & $102 / 102$ & Weak & 53 & No \\
\hline Nandakumar et al. [33] & 1990 & India & Case-control & $348 / 348$ & Moderate & 54.8 & No \\
\hline Sankaranarayanan et al. [31] & 1990 & India & Case-control & $414 / 895$ & Moderate & $\mathrm{n} / \mathrm{a}$ & Smoking and alcohol \\
\hline Rao et al. [34] & 1994 & India & Case-control & $713 / 635$ & Moderate & 50.35 & Smoking and alcohol \\
\hline Khan et al. [35] & 1995 & Pakistan & Case-control & $24 / 24$ & Moderate & 54 & No \\
\hline Wasnik et al. [36] & 1998 & India & Case-control & $123 / 246$ & Moderate & $\mathrm{n} / \mathrm{a}$ & No \\
\hline Dikshit and Kanhere [37] & 2000 & India & Case-control & $558 / 260$ & Moderate & $\mathrm{n} / \mathrm{a}$ & Smoking \\
\hline Merchant et al. [38] & 2000 & Pakistan & Case-control & $79 / 149$ & Moderate & 49 & Smoking and alcohol \\
\hline Balaram et al. [39] & 2002 & India & Case-control & $591 / 582$ & Moderate & $\mathrm{n} / \mathrm{a}$ & No \\
\hline Znaor et al. [40] & 2003 & India & Case-control & $1563 / 3638$ & Moderate & $\mathrm{n} / \mathrm{a}$ & Smoking and alcohol \\
\hline Subapriya et al. [41] & 2007 & India & Case-control & $388 / 388$ & Moderate & 50.85 & No \\
\hline Gangane et al. [42] & 2007 & India & Case-control & $140 / 380$ & Weak & $\mathrm{n} / \mathrm{a}$ & No \\
\hline Basu et al. [43] & 2008 & India & Case-control & $110 / 110$ & Weak & $\mathrm{n} / \mathrm{a}$ & No \\
\hline Muwonge et al. [44] & 2008 & India & Case-control & $282 / 1410$ & Moderate & $\mathrm{n} / \mathrm{a}$ & Smoking and alcohol \\
\hline Jayalekshmi et al. [45] & 2009 & India & Cohort study & $79593 / 92^{* *}$ & Moderate & $\mathrm{n} / \mathrm{a}$ & No \\
\hline Jayalekshmi et al. [46] & 2011 & India & Cohort study & $66277 / 160^{* *}$ & Moderate & $\mathrm{n} / \mathrm{a}$ & No \\
\hline Pednekar et al. [47] & 2011 & India & Cohort study & $87222 / 1267^{* *}$ & Moderate & $\mathrm{n} / \mathrm{a}$ & No \\
\hline Madani et al. [48] & 2012 & India & Case-control & $350 / 350$ & Moderate & $\mathrm{n} / \mathrm{a}$ & Smoking and alcohol \\
\hline Ray et al. [49] & 2013 & India & Case-control & $698 / 948$ & Weak & $\mathrm{n} / \mathrm{a}$ & No \\
\hline
\end{tabular}

"Based on the "Effective Public Health Project Quality Assessment Tool for Quantitative Studies".

${ }^{* *}$ Size of the cohort and the number of oral cancer cases in the cohort.

smoking had been done, when combined, provided a pooled OR of 4.3 [3.1-5.8]. The pooled OR from combining only case-control studies was 5.4 [4.1-7.1]. Case-control studies having hospitals as a source of controls when combined gave a pooled estimate of 4.2 [2.5-6.9]. Cohort studies when combined provided a pooled OR of 2.9 [1.1-8.3]. For studies carried out in India the pooled estimate was 4.8 [3.2-7.4]. For studies carried out in South India, which comprises of the states of Andhra Pradesh, Kerala, Karnataka, and Tamil Nadu, the pooled OR was 5.1 [3.3-8.1]. The pooled OR for studies carried out in the state of Maharashtra was 4.8 [1.713.5]. When studies of moderate quality were combined, the pooled estimate came out to be 4.5 [2.8-7.3]. The pooled estimate for studies ranked as "weak" was 5.2 [2.6-10.3].

3.1.1. Gender Differences. Three publications reported or contained data from which OR for men and/or women could be calculated separately (Table 2 ). Among men the OR ranged from 1.2 [1.0-1.4] [47] to 5.8 [3.6-9.5] [37]. Only two studies reported OR separately for women ranging from 6.4 [3.3-9.0] [49] to 25.3 [11.2-57.3] [33]. Studies carried out with only men taken as study subjects when combined provided a pooled OR of 4.0 [2.9-5.7].

\subsubsection{Exposure-Response Relationships}

Intensity/Frequency. A total of seven publications provided dose response relationships according to the intensity of daily usage as exposure metric (Table 2). These OR varied from 1.1 [1.0-1.4] [47] for chewing tobacco or chewable products containing tobacco for less than 5 times a day to 20.0 [8.1-48.9] [36] for more than 10 times a day compared to nonchewers; among studies adjusted for smoking and/or alcohol the corresponding values were 2.0 [1-3.8] and 13.9 [7.1-27.2], both coming from the same study done by Diskshit et al. [37].

Duration of Use. Six publications described the effect of chewing tobacco on developing oral cancer in terms of the total duration of the habit (Table 2). The OR varied from 


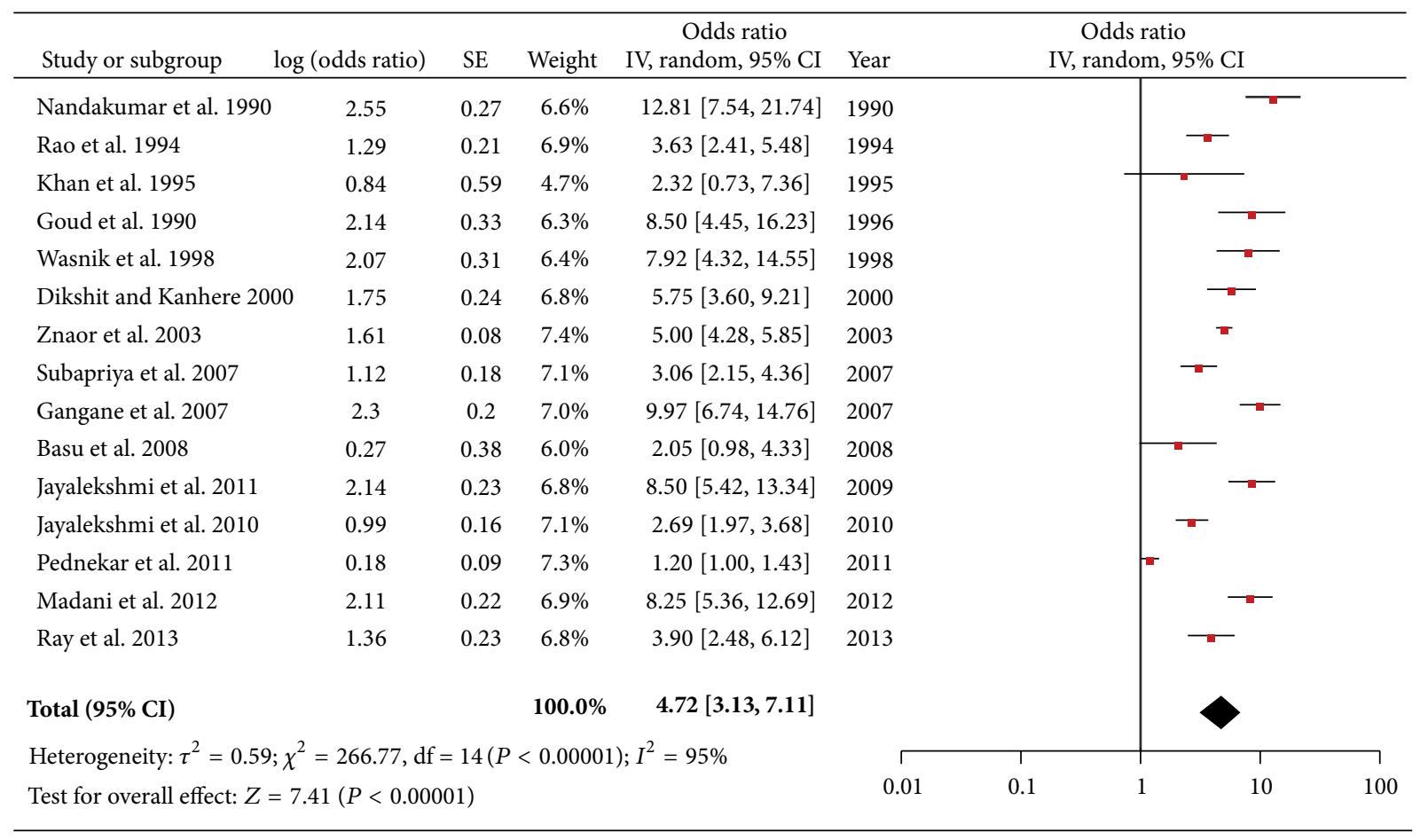

FIGURE 2: Forest plot of chewing tobacco and risk of oral cancer.

0.8 [0.4-1.7] [47] for the total duration of the habit being less than 10 years, compared to nonchewers, to 10.9 [5.9-20.0] [36] for a usage duration of 20 years or more compared to nonchewers.

3.2. Paan/Betel Quid (with Tobacco) and Oral Cancer. A total of nine publications included in this review reported OR or contained data from which OR could be calculated for the risk of chewing paan/betel quid and oral cancer (Table 3). Six publications [29-31, 38, 41, 44] reported overall OR which were adjusted for confounding factors such as smoking and/or alcohol. The adjusted OR varied from 3.1 [41] to 14.1 [7.4-26.5] [31]. Overall, the OR (both adjusted and unadjusted) varied from 3.1 [41] to 15.7 [11.0-22.1] [39]. The pooled OR for chewing paan/betel quid and risk of oral cancer was 7.1 [4.5-11.1] (Figure 3). The studies where adjustment for alcohol and/or smoking had been done, when combined, provided a pooled OR of 6.3 [3.9-10.2]. Casecontrol studies having hospitals as a source of controls when combined gave a pooled estimate of 7.4 [4.4-12.4]. For studies carried out in India the pooled estimate was 7.0 [4.4-11.1]. For studies carried out in South India the pooled OR was 7.4 [4.1-13.0]. Only one study was carried out in the state of Maharashtra where the OR was 9.3 [5.1-17.2]. When the one "weak" study, for which the OR was 3.9 [2.4-6.4], was excluded, the pooled estimate came out to be 7.6 [4.7-12.3]. Similarly the pooled risk estimates from studies carried out in South India were comparatively higher than the overall pooled estimate.

3.2.1. Gender Differences. Six studies reported or contained data from which OR could be calculated separately from men and/or women (Table 3). For men the OR for chewing betel quid with tobacco ranged from 1.5 [0.75-3.02] [49] to 10.9 [31]; among women the OR ranged between 6.5 [29] and 45.8 [25-84.1] [39].

\subsubsection{Exposure-Response Relationships}

Intensity/Frequency. Five studies reported the effect of frequency of daily use of paan with tobacco on oral cancer (Table 3). The OR varied from 3.3 [1.6-6.9] [29] for chewing paan with tobacco, for less than 5 times a day compared to nonchewers, to 24.7 [12.5-48.7] [39] for someone chewing it more than 10 times a day compared to nonchewers; for studies adjusted for smoking and/or alcohol the corresponding values were 3.3 [1.6-6.9] [29] and 15.7 [31].

Duration of Usage. Four studies reported OR for the total duration of habit and oral cancer (Table 3, last column). The OR for chewing habit duration varied from 3.4 [30] for a chewing habit of less than 10 years to 14.6 [30] for a chewing habit persisting for 20 years or more; the corresponding values for studies adjusting for smoking and/or alcohol were 3.4 and 14.6 both from the same study by Sankarnarayanan et al. [30].

\section{Discussion}

The results of this systematic review suggest a strong link between different forms of smokeless tobacco (SLT) and oral cancer and further strengthens and supports the IARC's take on SLT that it is a risk factor for oral cancer $[15,16]$. Users 


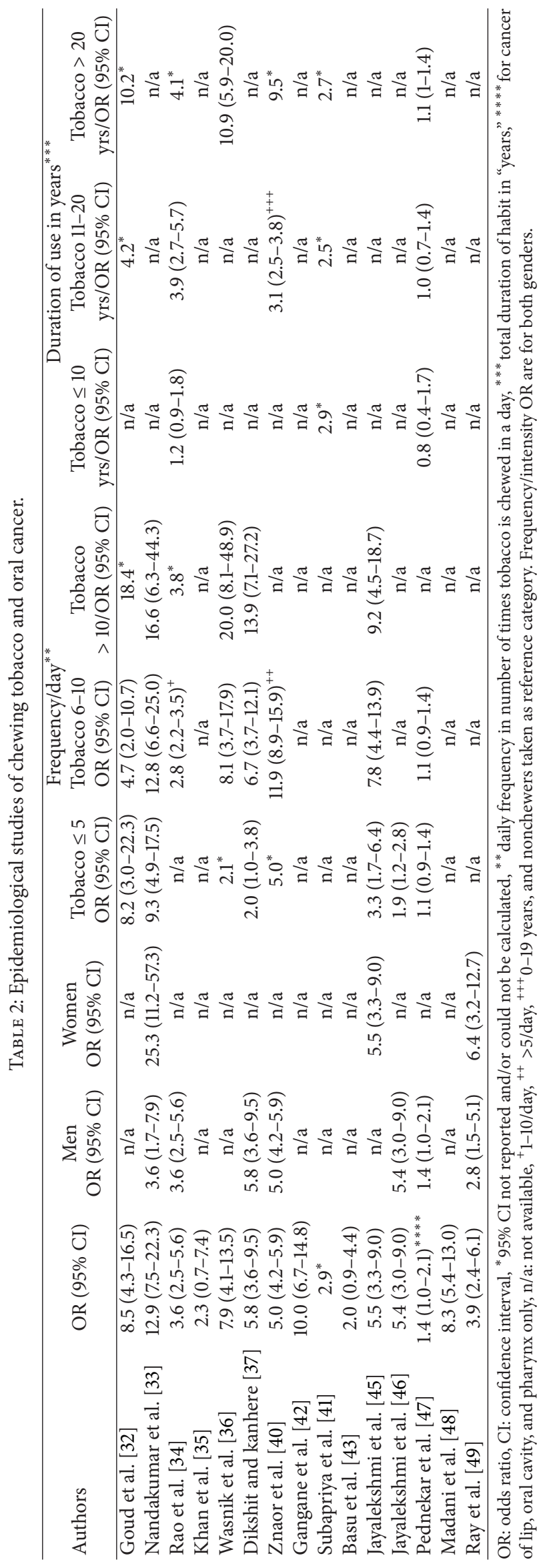




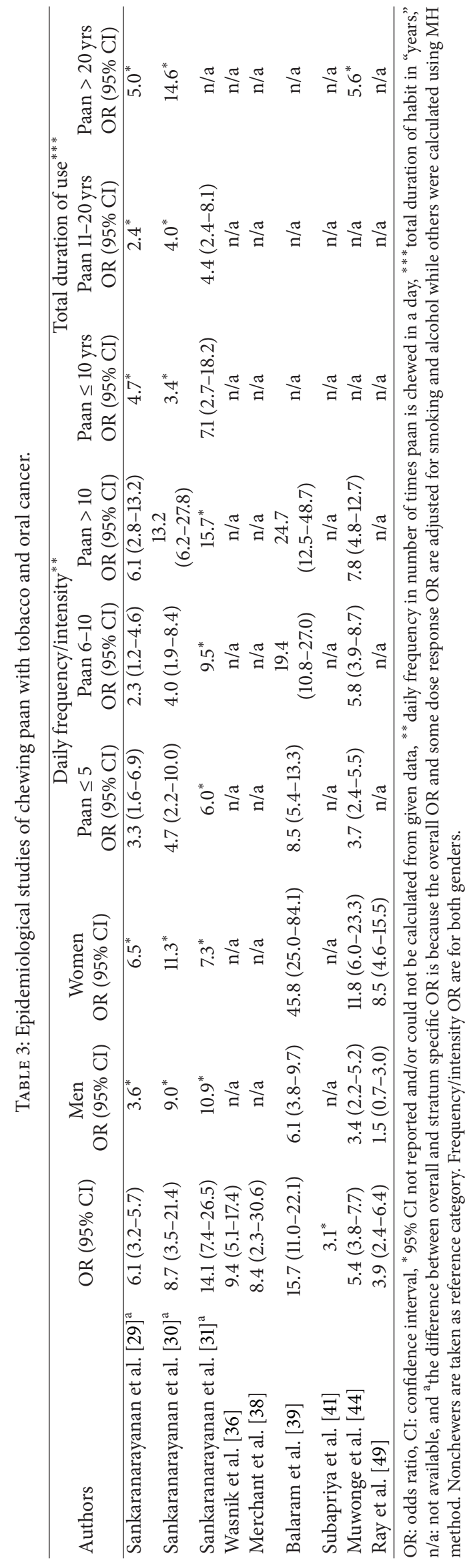




\begin{tabular}{|c|c|c|c|c|c|c|c|c|}
\hline \multirow{2}{*}{$\begin{array}{l}\text { Study or subgroup lo } \\
\text { Sankaranarayanan et al. } 1989\end{array}$} & og (odds ratio) & \multirow{2}{*}{$\begin{array}{c}\text { SE } \\
0.31\end{array}$} & \multirow{2}{*}{$\begin{array}{l}\text { Weight } \\
11.0 \%\end{array}$} & \multirow{2}{*}{$\begin{array}{c}\text { Odds ratio } \\
\text { IV, random, 95\% CI } \\
6.11[3.33,11.22]\end{array}$} & \multirow{2}{*}{$\begin{array}{l}\text { Year } \\
1989\end{array}$} & \multicolumn{2}{|c|}{$\begin{array}{l}\text { Odds ratio } \\
\text { IV, random, } 95 \% \mathrm{CI}\end{array}$} & \\
\hline & 1.81 & & & & & & 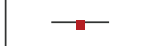 & \\
\hline Sankaranarayanan et al. 1989 & 2.16 & 0.29 & $11.3 \%$ & $8.67[4.91,15.31]$ & 1989 & & -- & \\
\hline Sankaranarayanan et al. 1990 & 2.64 & 0.32 & $10.8 \%$ & $14.01[7.48,26.24]$ & 1990 & & 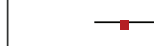 & \\
\hline Wasnik et al. 1998 & 2.24 & 0.31 & $11.0 \%$ & $9.39[5.12,17.25]$ & 1998 & & - & \\
\hline Merchant et al. 2000 & 2.13 & 0.66 & $6.3 \%$ & $8.41[2.31,30.68]$ & 2000 & & & \\
\hline Balaram et al. 2002 & 2.75 & 0.18 & $12.8 \%$ & $15.64[10.99,22.26]$ & 2002 & & $\pi$ & \\
\hline Subapriya et al. 2007 & 1.01 & 0.22 & $12.3 \%$ & $2.75[1.78,4.23]$ & 2007 & & $\rightarrow$ & \\
\hline Muwonge et al. 2008 & 1.68 & 0.18 & $12.8 \%$ & $5.37[3.77,7.64]$ & 2008 & & - & \\
\hline Ray et al. 2013 & 1.37 & 0.25 & $11.9 \%$ & $3.94[2.41,6.42]$ & 2013 & & 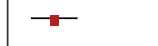 & \\
\hline Total (95\% CI) & & & $100.0 \%$ & $7.10[4.41,11.01]$ & & & & \\
\hline \multicolumn{5}{|c|}{ Heterogeneity: $\tau^{2}=0.36 ; \chi^{2}=51.96, \mathrm{df}=8(P<0.00001) ; I^{2}=85 \%$} & & . & T & $\neg$ \\
\hline \multicolumn{5}{|c|}{ Test for overall effect: $Z=8.75(P<0.00001)$} & 0.001 & 0.1 & 10 & 1000 \\
\hline
\end{tabular}

FIgURE 3: Forest plot of betel quid plus tobacco and the risk of oral cancer.

of betel quid with tobacco have a sevenfold higher risk for developing oral cancer as compared to nonchewers, OR 7.1 [4.5-11.1]. This finding is consistent with findings from the earlier reviews $[15,16]$. Similarly, people using other forms of SLT than betel quid with tobacco have an almost fivetime higher risk of developing oral cancer as compared to nonchewers, OR 4.7 [3.1-7.1]. These increased risks were consistently significant even after adjustment for other risks factors such as alcohol and smoking; that is, pooled OR for betel quid with tobacco after adjustment for alcohol and smoking was 6.3 [3.9-10.2] and the corresponding value for the chewing tobacco group was 4.3 [3.1-5.8]. These pooled estimates, however, should be dealt with caution because of the high levels of heterogeneity present among the studies but, despite indications of heterogeneity, even the lowest effect estimates among the individual studies are above the value of 1, pointing towards a causal link between SLT and oral cancer. The large variability of the effect estimates among individual studies may be attributed to differences in the composition of the products and population characteristics across the region. Additionally, although most studies are case-control design, there are differences between the sources and ratio of controls to the number of cases. In general, the three cohort studies provide relatively conservative estimates as compared to the case-control studies (Table 1).

For the chewing tobacco category, case-control studies provided a pooled estimate, OR 5.46 [4.1-7.1], which was significantly higher than that of the cohort studies, OR 2.9 [1.0-8.3]; albeit the pooled estimate for the cohort studies had an increased width of the confidence intervals. This finding is in contrast with the review done by Guha et al. [15], where they reported a higher pooled estimate for cohort studies as compared to the case-control ones. This may be explained by a difference in the selected cohort studies, as this review has only one cohort study in common with that review. They have included two cohort studies published prior to 1983, which might have reported considerably higher risk estimates. The source of controls had only a slight bearing on the pooled estimates, with the pooled OR for combining studies where controls were taken from hospitals, being slightly lower as compared to studies where population controls were recruited. This is consistent with previous findings [15]. The pooled OR for studies carried out in South India and the state of Maharashtra are relatively higher than the overall pooled estimate and this might be explained by the relatively high prevalence of SLT use in these geographic locations $[9,13,50]$ and incidence of oral cancer [51]. The quality of the combined studies had minimal effect on the overall summary estimate, that is, OR 4.5 [2.8-7.3], compared to the overall pooled OR of 4.7 [3.1-7.1]; however, in the chewing tobacco group exclusion of the weak studies $(n=4)$ lowered the pooled estimate, while in the betel quid group, where there was just one weak study, the overall estimate increased when the "weak" study was excluded. The studies which were ranked as "weak" did not play any role in the narrative synthesis either; most had not reported any results or suitable data for calculation of ORs, in the exposure response categories of frequency/intensity and duration.

Paan with tobacco appears to have a higher risk as compared to chewing other tobacco products; the overall pooled OR for paan as well as the pooled OR across different exposure strata are significantly higher in comparison with the other forms of chewing tobacco (Figure 3 and Tables 2 and 3). A possible reason for this could be the use of areca nut in paan, as it has been shown to have carcinogenic properties on its own [52] and thus might have a synergistic effect with the carcinogenicity of SLT, resulting in a higher risk of oral cancer as compared to other forms of SLT use. Similarly another ingredient, slaked lime, used in betel quid preparation has been shown to have carcinogenic potential. It facilitates the production of reactive oxygen species (ROS) in the saliva of chewers and also facilitates the hydrolysis of arecoline into arecaidine which in turn facilitates increased fibroblast proliferation and collagen synthesis, which are essential for premalignant and malignant transformation of the affected tissues [53]. The betel quid with tobacco group 
analysis included only case-control studies and therefore a formal comparison of the risk estimates among case-control and cohort studies could not be done. However, similar to the chewing tobacco group, the studies which recruited hospital controls had a relatively higher pooled risk estimate, that is, OR 7.4 [4.4-12.2], compared to the overall estimate.

An interesting observation is the risk differences among males and females, with females being at a significantly higher risk of oral cancer from SLT use as compared to men (Tables 2 and 3). This may be attributed to increased susceptibility of the female oral mucosa to damage by tobacco products [39] and relative lack of education and poverty, all of which have been shown to be significant risk factors on their own $[9,22]$. Also it may be due to a lower background risk for oral cancer among women of this region because of a lower prevalence of smoking and alcohol drinking [15]. Also a high prevalence of cervical cancer among women in India [54] may be suggestive of the presence of human papilloma virus (HPV) [55], which is an established risk factor for oral cancer as well. There is, however, significant inconsistency in effect estimates among the case-control studies regarding risks in women and also between the case-control and the cohort studies, which might have led to an overestimation of the risk estimates among women. In the study carried out by Jayalekshmi et al. where cohorts of men and women were analyzed separately [45, 46], the authors found that the risk estimates were almost similar among both sexes, which underscores the argument that the true effect size for the relationship between SLT and oral cancer in women may be overestimated. However, it should be clear that, regardless of the magnitude of effect size, all included studies that provide sex-specific estimates provide evidence that SLT is a major risk factor for oral cancer among women in the South Asian region. These results may warrant future research to specifically focus on sex differences and provide reliable risk estimates among men and women using SLT.

The results of our review suggest that there is an exposureresponse causal relationship between SLT use and oral cancer, for both the intensity and duration of use. This effect is somewhat linear in case of the chewing tobacco group but for the betel quid group, though the data suggests a possible relationship, it is a nonlinear one. This result is consistent with the IARC reviews but differs from findings of some other reviews [56-58] carried out on published literature from North America and Europe. In these reviews no dose response relationships were identified. This may be explained by the difference in the types of SLT used in South Asia compared to North America and Europe. Differences in ethnicity and socioeconomic status and environmental differences may be additional reasons for these conflicting findings. It may also be noted that the effect sizes reported in the reviews of studies carried out on SLT and oral cancer in Europe and North America report significantly smaller observed effect estimates as compared to the studies included in the present review. The synthesis of the reviewed publications suggests that the total duration of exposure to SLT increases the risk of oral cancer; that is, subjects who used SLT (chewing tobacco, paan/betel quid) for more than 10 years were at a higher risk of oral cancer than those who used SLT for less than
10 years. Parallels can be drawn here with the habit of smoking and alcohol use, where the risk for developing oral cancer increases with an increase in the total duration of exposure to these substances [59]. Furthermore, the mean age of oral cancer cases in the included studies was mostly in the fifth decade of life (Table 1). Given that usually habits like SLT use are generally taken up in early adolescence, this might suggest that prolonged exposure to SLT increases the risk of oral cancer, although age itself has been shown to be a risk factor for oral cancer.

\section{Limitations of the Review}

Some of the limitations are inherent to the observational study designs included in this systematic review, such as recall and selection bias, under-/overreporting of exposure status, retrospective exposure assessment, and uncontrolled confounding. Our electronic search included terms for all countries comprised in the South Asian region, but only publications from India and Pakistan were included because no case-control or cohort studies could be found for other countries. Therefore the results may not be applicable to the entire region. Due to a lack of resources a metaregression analysis could not be performed to identify the sources of heterogeneity; however, in the most recent review done by IARC researchers [15], which includes most of the studies included in our review, metaregression analysis did not lower heterogeneity to moderate or low levels.

\section{Policy Implications}

Given the various types of SLT used in the Indian subcontinent and its increasing popularity in the neighboring countries [60], it is of great importance that the general public be made aware of SLT use as a major risk factor for oral cancer. Most of the tobacco control initiatives around the world have been aimed towards cessation of smoking, where the main strategy to decrease smoking prevalence is the high amount of taxes levied on smoking products. Although this might be productive for smoking cessation, this strategy may facilitate an unintentional push towards smokeless tobacco use and increasing prevalence because SLT is cheaper compared to smoking. Additionally, big tobacco companies revert to manufacturing smokeless tobacco products and advertising them as less harmful than smoking [61]. All these scenarios may potentially lead to a surge in the use of smokeless tobacco products and subsequent increased risks for oral cancer for the general public. The governments and general public should be made aware of the potential dangers related to such approaches and may consider new programs for smokeless tobacco cessation or incorporate the risks of SLT consumption into smoking cessation programs.

\section{Conclusion}

From the published literature it appears that various forms of smokeless tobacco used in South Asia should be considered as strong risk factors for oral cancer. Public health policies 
in affected countries should consider SLT cessation programs in addition to campaigns and activities to inform the general public about SLT use and oral cancer risks.

\section{Conflict of Interests}

The authors declare that there is no conflict of interests regarding the publication of this paper.

\section{Authors' Contribution}

Zohaib Khan developed the concept for the study, conducted the literature search, assessed studies for quality and for inclusion in the review, and extracted data. He also prepared drafts and undertook edits. Justus Tönnies was involved in quality assessment, data extraction, and editing. Steffen Müller was involved in the development of the study concept, literature search, paper selection, and narrative synthesis. All authors contributed to the editing of the drafts and have read and approved all versions of the paper.

\section{Acknowledgments}

The authors would like to express their special appreciation and thanks to Professor Dr. Hajo Zeeb; without his valuable guidance and constant encouragement this paper would not have been possible. They also thank the reviewers for their valuable comments and critique.

\section{References}

[1] S. Warnakulasuriya, "Global epidemiology of oral and oropharyngeal cancer," Oral Oncology, vol. 45, no. 4-5, pp. 309-316, 2009.

[2] Oral Cancer Home Page-National Cancer Institute, 2014.

[3] J. Ma, Y. Liu, X. Yang, C. P. Zhang, Z. Y. Zhang, and L. P. Zhong, "Induction chemotherapy in patients with resectable head and neck squamous cell carcinoma: a meta-analysis," World Journal of Surgical Oncology, vol. 11, article 67, 2013.

[4] D. Upreti, A. Pathak, and S. K. Kung, "Lentiviral vector-based therapy in head and neck cancer," Oncology Letters, vol. 7, no. 1, pp. 3-9, 2014.

[5] A. Jemal, F. Bray, M. M. Center, J. Ferlay, E. Ward, and D. Forman, "Global cancer statistics," CA Cancer Journal for Clinicians, vol. 61, no. 2, pp. 69-90, 2011.

[6] "United Nations Statistics Division-Standard Country and Area Codes Classification," 2013, http://unstats.un.org/unsd/ methods/m49/m49regin.htm.

[7] International Agency for Research on Cancer, Globocan 2012, Fact Sheets by Population, http://globocan.iarc.fr/Pages/fact sheets_population.aspx.

[8] R. Ali and A. Finlayson, "Building capacity for clinical research in developing countries: the INDOX Cancer Research Network experience," Global Health Action, vol. 5, p. 10, 2012.

[9] P. C. Gupta and C. S. Ray, "Smokeless tobacco and health in India and South Asia," Respirology, vol. 8, no. 4, pp. 419-431, 2003.

[10] SEARO, "90\% of smokeless tobacco users live in South-East Asia," 2013, http://www.searo.who.int/mediacentre/releases/ 2013/pr1563/en/.
[11] S. Z. Imam, H. Nawaz, Y. J. Sepah, A. H. Pabaney, M. Ilyas, and S. Ghaffar, "Use of smokeless tobacco among groups of Pakistani medical students-a cross sectional study," BMC Public Health, vol. 7, article 231, 2007.

[12] M. I. Nisar and R. Iqbal, "Smokeless tobacco use prevention and cessation (S-TUPAC): a need of the time," Journal of the Pakistan Medical Association, vol. 61, no. 7, pp. 711-712, 2011.

[13] G. Bhawna, "Burden of smoked and smokeless tobacco consumption in India-results from the global adult tobacco survey india (GATS-India)- 2009-2010," Asian Pacific Journal of Cancer Prevention, vol. 14, no. 5, pp. 3323-3329, 2013.

[14] IARC Working Group on the Evaluation of Carcinogenic Risks to Humans, Smokeless Tobacco and Some Tobacco-Specific NNitrosamines, vol. 89 of IARC Monographs on the Evaluation of Carcinogenic Risks to Human, 2007.

[15] P. Boffetta, S. Hecht, N. Gray, P. Gupta, and K. Straif, "Smokeless tobacco and cancer," The Lancet Oncology, vol. 9, no. 7, pp. 667675, 2008.

[16] N. Guha, S. Warnakulasuriya, J. Vlaanderen, and K. Straif, "Betel quid chewing and the risk of oral and oropharyngeal cancers: a meta-analysis with implications for cancer control," International Journal of Cancer, 2013.

[17] R. Sankaranarayanan, "Oral cancer in India: an epidemiologic and clinical review," Oral Surgery Oral Medicine and Oral Pathology, vol. 69, no. 3, pp. 325-330, 1990.

[18] C. M. Allen, N. Vigneswaran, K. Tilashalski, B. Rodu, and P. Cole, "Tobacco use and cancer: a reappraisal," Oral Surgery, Oral Medicine, Oral Pathology, Oral Radiology and Endodontology, vol. 80, no. 2, pp. 178-182, 1995.

[19] P. C. Gupta, P. R. Murti, and R. B. Bhonsle, "Epidemiology of cancer by tobacco products and the significance of TSNA," Critical Reviews in Toxicology, vol. 26, no. 2, pp. 183-198, 1996.

[20] I. Chiba, "Prevention of betel quid chewers' oral cancer in the asian-pacific area," Asian Pacific Journal of Cancer Prevention, vol. 2, no. 4, pp. 263-269, 2001.

[21] J. A. Critchley and B. Unal, "Health effects associated with smokeless tobacco: a systematic review," Thorax, vol. 58, no. 5, pp. 435-443, 2003.

[22] M. Rani, S. Bonu, P. Jha, S. N. Nguyen, and L. Jamjoum, "Tobacco use in India: prevalence and predictors of smoking and chewing in a national cross sectional household survey," Tobacco Control, vol. 12, no. 4, p. e4, 2003.

[23] A. S. K. Sham, L. K. Cheung, L. J. Jin, and E. F. Corbet, "The effects of tobacco use on oral health," Hong Kong Medical Journal, vol. 9, no. 4, pp. 271-277, 2003.

[24] S. Warnakulasuriya, "Smokeless tobacco and oral cancer," Oral Diseases, vol. 10, no. 1, pp. 1-4, 2004.

[25] F. Javed, M. Chotai, A. Mehmood, and K. Almas, "Oral mucosal disorders associated with habitual gutka usage: a review," Oral Surgery, Oral Medicine, Oral Pathology, Oral Radiology and Endodontology, vol. 109, no. 6, pp. 857-864, 2010.

[26] P. C. Gupta, C. S. Ray, D. N. Sinha, and P. K. Singh, "Smokeless tobacco: a major public health problem in the SEA region: a review," Indian Journal of Public Health, vol. 55, no. 3, pp. 199209, 2011.

[27] "Effective Public Health Practice Project Quality Assessment tool for Quantitative Studies," http://www.ephpp.ca/tools.html.

[28] RevMan, The Cochrane IMS, http://tech.cochrane.org/revman.

[29] R. Sankaranarayanan, S. W. Duffy, N. E. Day, M. K. Nair, and G. Padmakumary, "A case-control investigation of cancer of the oral tongue and the floor of the mouth in Southern India," International Journal of Cancer, vol. 44, no. 4, pp. 617-621, 1989. 
[30] R. Sankaranarayanan, S. W. Duffy, G. Padmakumary, N. E. Day, and T. K. Padmanabhan, "Tobacco chewing, alcohol and nasal snuff in cancer of the gingiva in Kerala, India," British Journal of Cancer, vol. 60, no. 4, pp. 638-643, 1989.

[31] R. Sankaranarayanan, S. W. Duffy, G. Padmakumary, N. E. Day, and M. K. Nair, "Risk factors for cancer of the buccal and labial mucosa in Kerala, Southern India," Journal of Epidemiology and Community Health, vol. 44, no. 4, pp. 286-292, 1990.

[32] M. L. Goud, S. C. Mohapatra, P. Mohapatra, S. D. Gaur, G. C. Pant, and M. N. Knanna, "Epidemiological correlates between consumption of Indian chewing tobacco and oral cancer," European Journal of Epidemiology, vol. 6, no. 2, pp. 219-222, 1990.

[33] A. Nandakumar, K. T. Thimmasetty, N. M. Sreeramareddy, T. C. Venugopal, A. T. Vinutha, and M. K. Bhargava, "A populationbased case-control investigation on cancers of the oral cavity in Bangalore, India," British Journal of Cancer, vol. 62, no. 5, pp. 847-851, 1990.

[34] D. N. Rao, B. Ganesh, R. S. Rao, and P. B. Desai, "Risk assessment of tobacco, alcohol and diet in oral cancer. A case-control study," International Journal of Cancer, vol. 58, no. 4, pp. 469-473, 1994.

[35] S. A. Khan, J. Ajetunmobi, R. J. Jewers et al., "Risk factors associated with oral carcinoma in Pakistan," Cancer Journal, vol. 8, no. 4, pp. 206-210, 1995.

[36] K. S. Wasnik, S. N. Ughade, S. P. Zodpey, and Ingole D. L., "Tobacco consumption practices and risk of oro-pharyngeal cancer: a case-control study in Central India," Southeast Asian Journal of Tropical Medicine and Public Health, vol. 29, no. 4, pp. 827-834, 1998.

[37] R. P. Dikshit and S. Kanhere, "Tobacco habits and risk of lung, oropharyngeal and oral cavity cancer: a population-based case-control study in Bhopal, India," International Journal of Epidemiology, vol. 29, no. 4, pp. 609-614, 2000.

[38] A. Merchant, S. S. M. Husain, M. Hosain et al., "Paan without tobacco: an independent risk factor for oral cancer," International Journal of Cancer, vol. 86, no. 1, pp. 128-131, 2000.

[39] P. Balaram, H. Sridhar, T. Rajkumar et al., "Oral cancer in Southern India: the influence of smoking, drinking, paanchewing and oral hygiene," International Journal of Cancer, vol. 98, no. 3, pp. 440-445, 2002.

[40] A. Znaor, P. Brennan, V. Gajalakshmi et al., "Independent and combined effects of tobacco smoking, chewing and alcohol drinking on the risk of oral, pharyngeal and esophageal cancers in Indian men," International Journal of Cancer, vol. 105, no. 5, pp. 681-686, 2003.

[41] R. Subapriya, A. Thangavelu, B. Mathavan, C. R. Ramachandran, and S. Nagini, "Assessment of risk factors for oral squamous cell carcinoma in Chidambaram, southern India: a case-control study," European Journal of Cancer Prevention, vol. 16, no. 3, pp. 251-256, 2007.

[42] N. Gangane, S. Chawla, S. S. Gupta, and S. M. Sharma, "Reassessment of risk factors for oral cancer," Asian Pacific Journal of Cancer Prevention, vol. 8, no. 2, pp. 243-248, 2007.

[43] R. Basu, S. Mandal, A. Ghosh, and T. K. Poddar, "Role of tobacco in the development of head and neck squamous cell carcinoma in an eastern Indian population," Asian Pacific Journal of Cancer Prevention, vol. 9, no. 3, pp. 381-386, 2008.

[44] R. Muwonge, K. Ramadas, R. Sankila et al., "Role of tobacco smoking, chewing and alcohol drinking in the risk of oral cancer in Trivandrum, India: a nested case-control design using incident cancer cases," Oral Oncology, vol. 44, no. 5, pp. 446454, 2008.
[45] P. A. Jayalekshmi, P. Gangadharan, S. Akiba, R. R. K. Nair, M. Tsuji, and B. Rajan, "Tobacco chewing and female oral cavity cancer risk in Karunagappally cohort, India," British Journal of Cancer, vol. 100, no. 5, pp. 848-852, 2009.

[46] P. A. Jayalekshmi, P. Gangadharan, S. Akiba, C. Koriyama, and R. R. K. Nair, "Oral cavity cancer risk in relation to tobacco chewing and bidi smoking among men in Karunagappally, Kerala, India: Karunagappally cohort study," Cancer Science, vol. 102, no. 2, pp. 460-467, 2011.

[47] M. S. Pednekar, P. C. Gupta, B. B. Yeole, and J. R. Hébert, "Association of tobacco habits, including bidi smoking, with overall and site-specific cancer incidence: Results from the Mumbai cohort study," Cancer Causes and Control, vol. 22, no. 6, pp. 859-868, 2011.

[48] A. H. Madani, M. Dikshit, and D. Bhaduri, "Risk for oral cancer associated to smoking, smokeless and oral dip products," Indian Journal of Public Health, vol. 56, no. 1, pp. 57-60, 2012.

[49] J. G. Ray, M. Ganguly, B. H. Rao Sripathi, S. Mukherjee, B. Mahato, and K. Chaudhuri, "Clinico-epidemiological profile of oral potentially malignant and malignant conditions among areca nut, tobacco and alcohol users in Eastern India: a hospital based study," Journal of Oral and Maxillofacial Pathology, vol. 17, no. 1, pp. 45-50, 2013.

[50] T. Rooban, E. Joshua, U. K. Rao, and K. Ranganathan, "Prevalence of chewable smokeless tobacco in Indian women: secondary data analysis from national family health survey 200506," Journal of Dr. NTR University of Health Sciences, vol. 2, pp. 29-35, 2014.

[51] K. R. Coelho, "Challenges of the oral cancer burden in India," Journal of Cancer Epidemiology, vol. 2012, Article ID 701932, 17 pages, 2012.

[52] D. C. Sharma, "Betel quid and areca nut are carcinogenic without tobacco," The Lancet Oncology, vol. 4, no. 10, p. 587, 2003.

[53] M. Singh, S. Mehrotra, N. Kalra, U. Singh, and Y. Shukla, "Correlation of DNA ploidy with progression of cervical cancer," Journal of Cancer Epidemiology, vol. 2008, Article ID 298495, 7 pages, 2008.

[54] A. Nandakumar, T. Ramnath, and M. Chaturvedi, "The magnitude of cancer cervix in India," Indian Journal of Medical Research, vol. 130, no. 3, pp. 219-221, 2009.

[55] R. N. Sharan, R. Mehrotra, Y. Choudhury, and K. Asotra, "Association of Betel nut with carcinogenesis: revisit with a clinical perspective," PLoS ONE, vol. 7, no. 8, Article ID e42759, 2012.

[56] P. N. Lee and J. Hamling, "Systematic review of the relation between smokeless tobacco and cancer in Europe and North America," BMC Medicine, vol. 7, article 36, 2009.

[57] R. Weitkunat, E. Sanders, and P. N. Lee, "Meta-analysis of the relation between European and American smokeless tobacco and oral cancer," BMC Public Health, vol. 7, article 334, 2007.

[58] P. N. Lee, "Summary of the epidemiological evidence relating snus to health," Regulatory Toxicology and Pharmacology, vol. 59, no. 2, pp. 197-214, 2011.

[59] W. J. Blot, J. K. McLaughlin, D. M. Winn et al., "Smoking and drinking in relation to oral and pharyngeal cancer," Cancer Research, vol. 48, no. 11, pp. 3282-3287, 1988.

[60] T. M. Mack, "The new pan-Asian paan problem," The Lancet, vol. 357, no. 9269, pp. 1638-1639, 2001.

[61] K. Krisberg, "New types of smokeless tobacco present growing risks for youth: survey: products mistaken for candy," The Nation's Health, vol. 40, no. 6, pp. 1-14, 2010. 


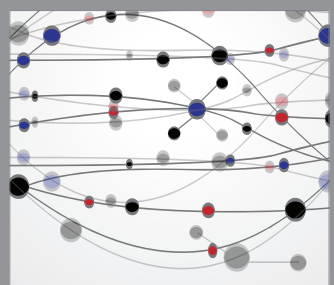

The Scientific World Journal
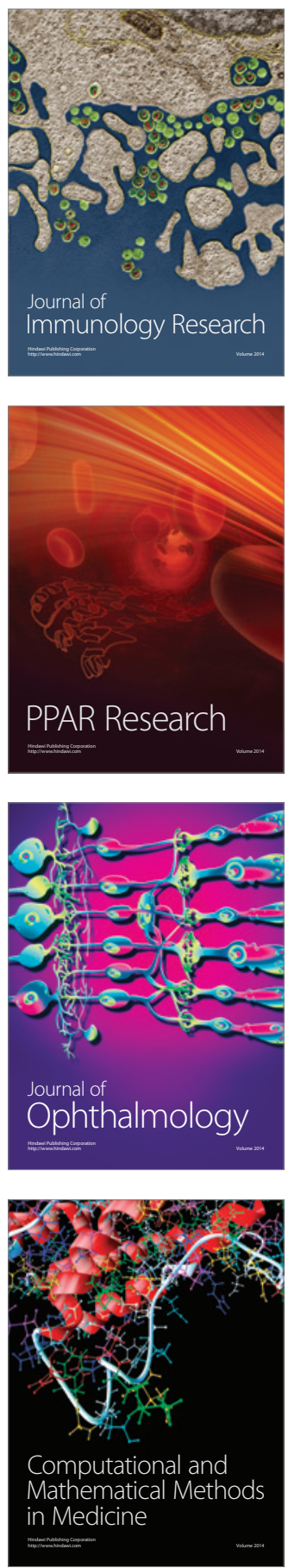

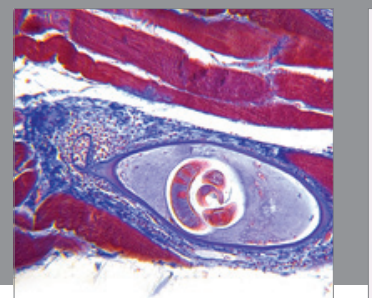

Gastroenterology

Research and Practice
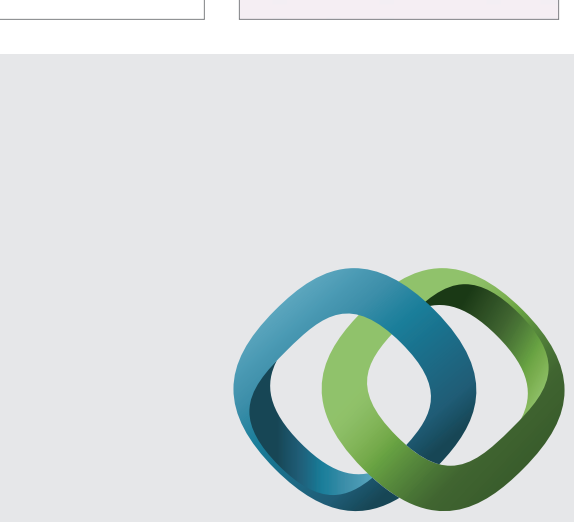

\section{Hindawi}

Submit your manuscripts at

http://www.hindawi.com
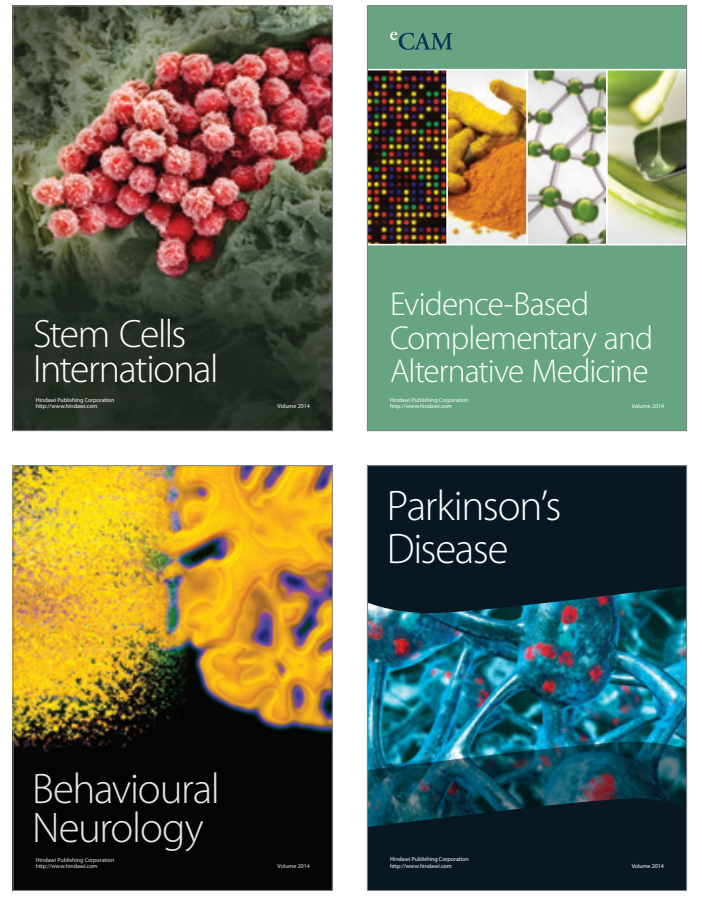
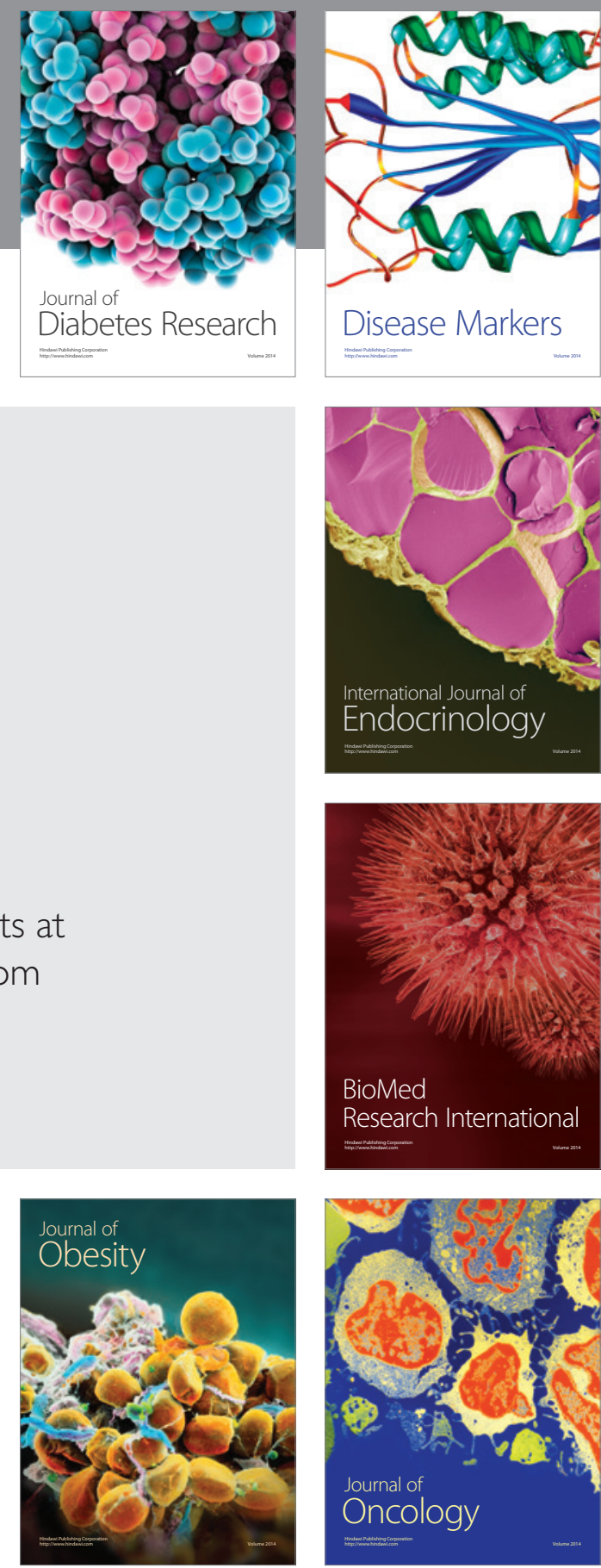

Disease Markers
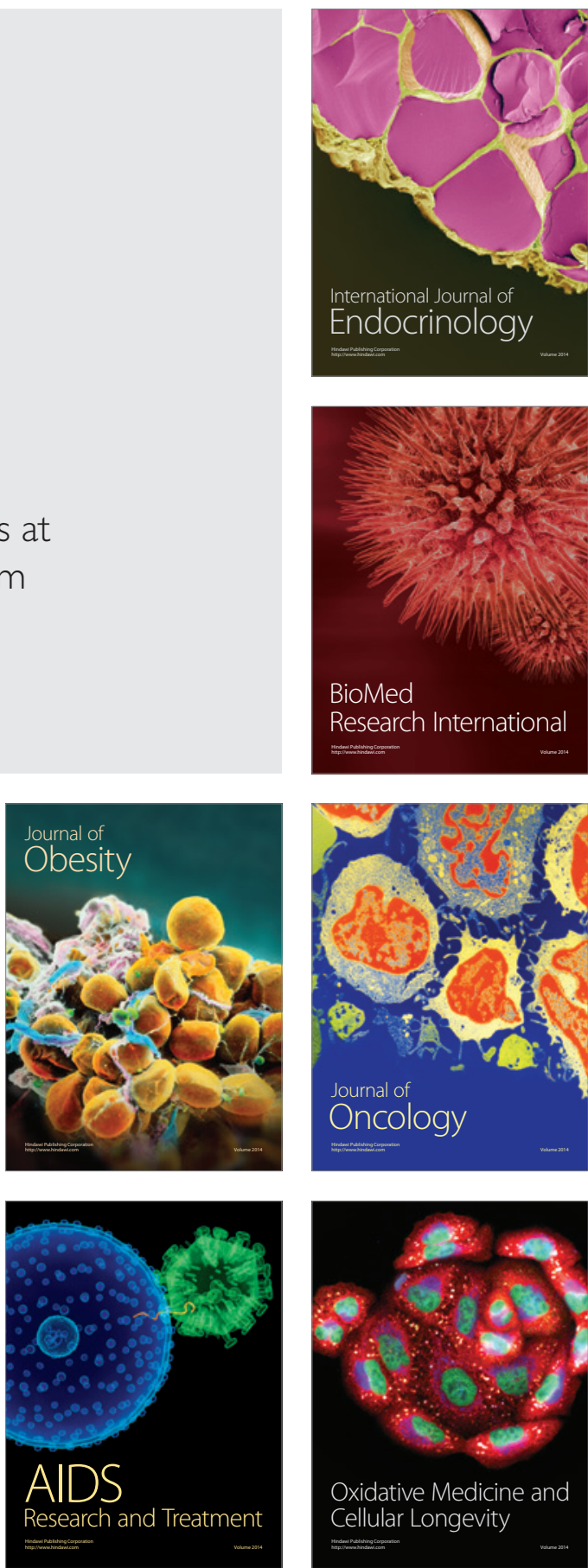